\title{
Efeito de palhadas e métodos de irrigações na supressão de plantas daninhas
}

\author{
Effect of straws and irrigation methods in suppression of weeds
}

\section{Naiara Guerra ${ }^{1 *}$, Antonio Mendes de Oliveira Neto ${ }^{2,3}$, Rodrigo Flora ${ }^{4}$, Angélica Guerra ${ }^{5}$, Leandro Meert ${ }^{4}$ e Eduardo Leonel Bottega ${ }^{1}$}

\author{
Recebido em 20/07/2015 / Aceito em 23/10/2015
}

\section{RESUMO}

Dois experimentos foram conduzidos com o objetivo de avaliar a influência de palhadas de diferentes culturas submetidas a dois métodos de irrigação na supressão do desenvolvimento das plantas daninhas Ipomoea triloba e Euphorbia heterophylla. Os ensaios foram conduzidos no campus da Faculdade Integrado de Campo Mourão - PR durante os meses de setembro e outubro de 2014. Os tratamentos foram dispostos em esquema fatorial $2 \times 6$, o primeiro fator foi representado por dois métodos de irrigação, sendo estes superficial e subsuperficial e o segundo por cinco tipos de palha (girassol, nabo forrageiro, aveia, feijão e trigo) e uma testemunha sem a presença de palhada. Foram realizadas avaliações de número de plantas e número de folhas de I. triloba e E. heterophylla aos 7, 14, 21 e 28 DAA, sendo que na última avalição foi realizada a coleta da parte área da planta para obtenção da massa seca. De maneira geral, verificou-se que as palhadas de nabo forrageiro, aveia, feijão e trigo, quando recebem irrigação superficial, promovem menor desenvolvimento das plantas de corda-de-viola e menor acúmulo de massa seca para as plantas de leiteiro.

PALAVRAS-CHAVE: alelopatia, Euphorbia heterophylla, Ipomoea triloba, plantio direto.

\section{ABSTRACT}

Two experiments were conducted in order to evaluate the influence of straws of different cultures subjected to two methods of irrigation in suppressing the development of weeds Ipomoea triloba and Euphorbia heterophylla. The tests were conducted on the campus of the Integrated College of Campo Mourão - PR during the months of September and October 2014. The treatments were arranged in a factorial design $2 \times 6$, the first factor was represented by two irrigation methods, which are superficial and subsurface and the second for five types of straw (sunflower, turnip, oats, beans and wheat) and a control without the presence of straw. Plant number evaluations were performed and number of leaves of I. triloba and E. heterophylla at $7,14,21$, and $28 \mathrm{DAA}$, and in the last evaluation collecting area of the plant to obtain the dry weight was carried out. Overall, it was found that the turnip, oats, beans, and wheat, when they receive surface irrigation, promote smaller development of morningglory plants and lower dry mass accumulation of poinsettia plants.

KEYWORDS: allelopathy, Euphorbia heterophylla, Ipomoea triloba, no-tillage.

\section{INTRODUÇÃO}

A cobertura do solo pelos restos culturais, além de contribuir na melhoria das características físicas, químicas e biológicas do solo e na manutenção da temperatura e da umidade do mesmo, pode ser um importante instrumento para auxiliar no controle das plantas daninhas (NOCE et al. 2008).

A capacidade de supressão de plantas daninhas por palhadas de culturas é bastante conhecida e explorada. Embora seja pouco pesquisada a importância relativa dos efeitos físicos e alelopáticos

\footnotetext{
${ }^{1}$ Universidade Federal de Santa Catarina, Curitibanos, SC, Brasil.

${ }^{2}$ Universidade Federal de Pelotas, Pelotas, RS, Brasil.

${ }^{3}$ Empresa de Pesquisa Agropecuária e Extensão Rural de Santa Catarina, Itajaí, SC, Brasil.

${ }^{4}$ Faculdade Integrado de Campo Mourão, Campo Mourão, PR, Brasil.

${ }^{5}$ Universidade Estadual do Mato Grosso do Sul, Campo Grande, MS, Brasil.

*Autor para correspondência <naiaraguerra.ng@gmail.com>.
} 
sobre esse fenômeno (TREZZI \& VIDAL 2004).

A supressão de plantas daninhas por coberturas mortas é atribuída a fatores de natureza física, química e biológica. Os efeitos físicos gerados pela palha estão relacionados principalmente à redução da disponibilidade da radiação solar e à redução da amplitude térmica na camada superficial do solo inibindo a germinação das sementes e dificultando o crescimento inicial das plântulas (NOCE et al. 2008). Este efeito é importante para sementes fotoblásticas positivas e para aquelas que necessitem de grande amplitude de variação térmica diária para iniciar o processo germinativo, além disso, esta barreira física reduz a chance de sobrevivência de plântulas com pequena quantidade de reserva na semente (PITELLI \& DURIGAN 2001, CORREIA et al. 2006).

O efeito químico esta relacionado a compostos alelopáticos com capacidade de suprimir o crescimento da planta daninha (TREZZI \& VIDAL 2004). De acordo com RICE (1984) a alelopatia é qualquer efeito direto ou indireto, benéfico ou prejudicial de uma espécie doadora a uma espécie receptora, podendo ser de uma planta ou de um microrganismo sobre outra planta, mediante produção de compostos químicos resultantes do metabolismo secundário que são liberados no meio. A alelopatia é conhecida como um importante mecanismo ecológico que influencia a dominância vegetal, a sucessão, formação de comunidades vegetais e de vegetação de clímax, bem como a produtividade e manejo de culturas (MIRÓ et al. 1997).

As substâncias alelopáticas são encontradas distribuídas em concentrações variadas em diferentes partes da planta e durante seu ciclo de vida. Quando essas substâncias são liberadas em quantidades suficientes causam inibição ou estímulo (variando com a concentração) da germinação, crescimento e/ ou desenvolvimento de plantas já estabelecidas e, no desenvolvimento de microrganismos (CARVALHO 1993).

No cultivo orgânico, sob semeadura direta, recomenda-se o pré-cultivo de espécies que produzam grande quantidade de palha, possibilitando a cobertura do solo para reduzir as plantas daninhas (MELO et al. 2007). Os resultados obtidos por esses autores mostram que as práticas adotadas no cultivo de milhoverde orgânico, sob sistema de semeadura direta, apresentam bom resultado no manejo de plantas daninhas quando da adoção de cobertura do solo com palha de aveia preta. GABRIEL FILHO et al.
(2003) verificaram que o efeito alelopático, influencia a germinação de várias espécies de plantas daninhas, reduzindo a competição com a cultura da mandioca $\mathrm{e}$, reduzindo significativamente, a interferência destas na produtividade da cultura.

Com base nessas informações o presente trabalho teve como objetivo avaliar a influência de palhadas de diferentes culturas submetidas à dois métodos de irrigação na supressão do desenvolvimento das plantas daninhas Ipomoea triloba e Euphorbia heterophylla.

\section{MATERIAL E MÉTODOS}

Dois experimentos foram conduzidos em viveiro protegido no Campus Experimental da Faculdade Integrado de Campo Mourão - PR, localizado na Rodovia BR 158, km 207, Jardim Batel, Campo Mourão - PR (latitude 2399'04” Sul, longitude 52 36'37' Oeste e altitude média de 508 metros), durante os meses de setembro e outubro de 2014.

No primeiro experimento foi testado o efeito da palhada no desenvolvimento da planta daninha $I$. triloba e no segundo sobre o desenvolvimento de $E$. heterophylla.

O delineamento experimental utilizado em ambos os ensaios foi o inteiramente casualizado, com quatro repetições. Os tratamentos foram dispostos em esquema fatorial $2 \times 6$, o primeiro fator foi representado por dois métodos de irrigação, sendo estes superficial (irrigação por cima da palhada) e subsuperficial (irrigação por capilaridade, através de um prato que foi colocado embaixo de cada vaso) e o segundo por cinco tipos de palha (girassol, nabo forrageiro, aveia, feijão e trigo) e uma testemunha sem a presença de palhada.

As unidades experimentais foram representadas por vasos de polietileno com capacidade de $8 \mathrm{~kg}$ de substrato. Estes vasos foram preenchidos com solo classificado como Latossolo Vermelho Distroférrico de textura muito argilosa (EMBRAPA 2013), sendo constituído por $76 \%$ de argila, $13 \%$ de areia e $11 \%$ de silte, $\mathrm{pH} 5,99$ e 2,3\% de matéria orgânica.

O experimento foi instalado no dia 15 de setembro de 2014 e seguiu a seguinte sequência: preenchimento dos vasos com o substrato, semeadura das plantas daninhas, cobertura com a palha e irrigação dos vasos.

As espécies avaliadas em cada experimento 
foram corda-de-viola (I. triloba) e leiteiro ( $E$. heterophylla). Após o preenchimento dos vasos com o substrato procedeu-se a semeadura das plantas daninhas (20 sementes por vaso).

Após a semeadura os vasos receberam a quantidade de palha correspondendo a 6 toneladas por hectare. Para todos os tipos de palhada testados foi utilizada a mesma quantidade para não haver diferença no efeito físico destas palhadas sobre o desenvolvimento das plantas daninhas.

Depois do acondicionamento da palha nos vasos foi realizada a irrigação. Foram utilizados dois métodos de irrigação (superficial e subsuperficial), a fim de eliminar o efeito químico a partir do efeito físico exercido pela palha. $\mathrm{O}$ primeiro método consistiu da irrigação superficial dos vasos, simulando uma situação de precipitação. O segundo consistiu em uma irrigação subsuperficial fornecendo água para as unidades experimentais, de modo que não houvesse fluxo de água através da palha, assim, umedecendo o solo por capilaridade de forma semelhante à descrita por OLIVEIRA JÚNIOR et al. (2014).

As avaliações realizadas neste experimento foram: número de plantas daninhas por vaso e número de folhas das plantas daninhas aos 7, 14, 21 e 28 dias após a emergência (DAE) e na última avaliação (28 DAE) foi feito a coleta da parte aérea das plantas daninhas presentes nos vasos. Este material foi acondicionado em sacos de papel e levados para a estufa de circulação de ar forçado à $65{ }^{\circ} \mathrm{C}$ com a finalidade de se determinar a massa seca das plantas daninhas.

Os dados foram submetidos à análise de variância, pelo teste $\mathrm{F}$ e teste de Scott-knott a 5\% de probabilidade. Todas as análises foram realizadas com auxílio do programa estatístico Sisvar (FERREIRA 2011).

\section{RESULTADOS E DISCUSSÃO}

Na Tabela 1 estão apresentados os resultados de número de plantas de corda-de-viola nas avaliações realizadas aos 7, 14, 21 e 28 DAE.

De acordo com os resultados obtidos, verificouse que aos $7 \mathrm{DAE}$, quando a adição de água foi realizada por cima da palhada (superficial), obtevese uma redução significativa no número de plantas de corda-de-viola nos vasos com palha de nabo forrageiro e feijão. Nas avaliações aos 14, 21 e 28 DAE as palhas de nabo forrageiro e feijão não diferiram quanto às demais palhas testadas. No entanto, notou-se uma tendência de menor emergência de corda-de-viola nos tratamentos com palhada de nabo forrageiro e feijão e irrigação superficial.

Comparando o número de plântulas emergidas em cada uma das avaliações é possível verificar que as palhadas de nabo forrageiro e feijão proporcionaram um atraso na emergência da cordade-viola. A vantagem no atraso na emergência das plantas daninhas seria o aumento do período de tempo para realização do controle adequado, o que tornaria mais eficiente a operação em condições de campo (MORAES et al. 2011).

MORAES et al. (2011) verificaram que resíduos vegetais de nabo forrageiro, incorporado ao solo, foram responsáveis pela redução no índice de velocidade de emergência e porcentagem de emergência de Digitaria spp.. Resíduos culturais de brassicas contém glucosinolatos, que podem afetar a germinação e reduzir o estabelecimento e crescimento de plantas daninhas (NORSWORTHY 2003, HARAMOTO \& GALLANDT 2004). O efeito alelopático do nabo forrageiro ficou mais evidente quando se compara os resultados entre os diferentes métodos de irrigação. Quando não houve molhamento da palhada (irrigação subsuperficial) não se observou diferença na emergência da corda-de-viola, isso ocorreu devido ao isolamento do efeito alelopático.

Quando a irrigação foi realizada por capilaridade (subsuperficial) não foram encontradas diferenças significativas entre as palhadas. Porém, verificou-se que quando foi utilizada a aveia como cobertura encontrou-se menor número de plantas de corda-de-viola, isso se deve ao efeito físico da camada de palha sobre o solo. De acordo com PIRES et al. (2008) a cobertura do solo limita a passagem de luz e forma um obstáculo inibindo a germinação de sementes e prejudicando o crescimento inicial das plantas daninhas.

Na Tabela 2 estão apresentados os resultados obtidos em relação ao número de folhas das plantas de corda-de-viola (I. triloba).

Verificou-se que quando a irrigação foi por capilaridade não foram obtidas diferenças significativas entre as palhadas, em nenhuma das avaliações.

Para a irrigação feita por cima da palha (superficial), nas avaliações aos 7, 14 e 21 DAE, o número de folhas de corda-de-viola foi semelhante para as diferentes palhadas testadas. 
Tabela 1 - Número de plantas de corda de viola (Ipomoea triloba) após a emergência em solos com diferentes coberturas vegetais. Campo Mourão, 2014.

Table 1- Number of morning glory plants (Ipomoea triloba) after emergence in soils with different vegetation cover. Campo Mourão, 2014.

\begin{tabular}{|c|c|c|c|c|c|c|c|c|}
\hline \multirow{3}{*}{ Palhada } & \multicolumn{8}{|c|}{ Número de plantas de corda de viola } \\
\hline & \multicolumn{2}{|c|}{$7 \mathrm{DAE}$} & \multicolumn{2}{|c|}{$14 \mathrm{DAE}$} & \multicolumn{2}{|c|}{$21 \mathrm{DAE}$} & \multicolumn{2}{|c|}{$28 \mathrm{DAE}$} \\
\hline & Sup. & Sub. & Sup. & Sub. & Sup. & Sub. & Sup. & Sub. \\
\hline Sem palha & $9,7 \mathrm{aA}$ & $3,2 \mathrm{aB}$ & $9,7 \mathrm{aA}$ & $4,7 \mathrm{aB}$ & $9,7 \mathrm{aA}$ & $4,7 \mathrm{aB}$ & $9,7 \mathrm{aA}$ & $4,7 \mathrm{aB}$ \\
\hline Girassol & $9,0 \mathrm{aA}$ & $3,5 \mathrm{aB}$ & $9,2 \mathrm{aA}$ & $6,0 \mathrm{aA}$ & $9,2 \mathrm{aA}$ & $6,0 \mathrm{aA}$ & $9,5 \mathrm{aA}$ & $6,5 \mathrm{aA}$ \\
\hline Nabo forrageiro & $5,5 \mathrm{bA}$ & $3,7 \mathrm{aA}$ & $7,0 \mathrm{aA}$ & $5,0 \mathrm{aA}$ & $7,0 \mathrm{aA}$ & $5,2 \mathrm{aA}$ & $7,0 \mathrm{aA}$ & $5,2 \mathrm{aA}$ \\
\hline Aveia & $8,5 \mathrm{aA}$ & $2,5 \mathrm{aB}$ & $9,0 \mathrm{aA}$ & $3,7 \mathrm{aB}$ & $9,0 \mathrm{aA}$ & $3,7 \mathrm{aB}$ & $9,0 \mathrm{aA}$ & $3,7 \mathrm{aB}$ \\
\hline Feijão & $6,0 \mathrm{bA}$ & $4,2 \mathrm{aA}$ & $6,2 \mathrm{aA}$ & $7,0 \mathrm{aA}$ & $6,2 \mathrm{aA}$ & $7,0 \mathrm{aA}$ & $6,2 \mathrm{aA}$ & $7,0 \mathrm{aA}$ \\
\hline Trigo & $8,2 \mathrm{aA}$ & $3,7 \mathrm{aB}$ & $9,0 \mathrm{aA}$ & $7,0 \mathrm{aA}$ & $9,0 \mathrm{aA}$ & $7,0 \mathrm{aA}$ & $9,0 \mathrm{aA}$ & $7,0 \mathrm{aA}$ \\
\hline Fcalc & \multicolumn{2}{|c|}{2,89} & \multicolumn{2}{|c|}{1,66} & \multicolumn{2}{|c|}{1,70} & \multicolumn{2}{|c|}{1,72} \\
\hline $\mathrm{CV}(\%)$ & \multicolumn{2}{|c|}{30,92} & \multicolumn{2}{|c|}{35,08} & \multicolumn{2}{|c|}{34,87} & \multicolumn{2}{|c|}{34,26} \\
\hline
\end{tabular}

Médias seguidas da mesma letra minúscula na coluna e maiúscula na linha não diferem entre si segundo o teste de Scott-Knott à 5\% de probabilidade.

Tabela 2 - Número de folhas das plantas de corda-de-viola (Ipomoea triloba) após a emergência em solos com diferentes coberturas vegetais. Campo Mourão, 2014.

Table 2 - Number of morning glory leaves (Ipomoea triloba) after emergence in soils with different vegetation cover. Campo Mourão, 2014.

\begin{tabular}{|c|c|c|c|c|c|c|c|c|}
\hline \multirow{3}{*}{ Palhada } & \multicolumn{8}{|c|}{ Número de folhas de plantas de corda de viola } \\
\hline & \multicolumn{2}{|c|}{$7 \mathrm{DAE}$} & \multicolumn{2}{|c|}{$14 \mathrm{DAE}$} & \multicolumn{2}{|c|}{$21 \mathrm{DAE}$} & \multicolumn{2}{|c|}{$28 \mathrm{DAE}$} \\
\hline & Sup. & Sub. & Sup. & Sub. & Sup. & Sub. & Sup. & Sub. \\
\hline Sem palha & 1,0 & 1,0 & $2,0 \mathrm{aA}$ & $1,5 \mathrm{aB}$ & $6,0 \mathrm{aA}$ & $6,0 \mathrm{aA}$ & $21,5 \mathrm{bA}$ & $16,0 \mathrm{aB}$ \\
\hline Girassol & 1,0 & 1,0 & $2,0 \mathrm{aA}$ & $1,5 \mathrm{aB}$ & $5,0 \mathrm{aB}$ & $7,0 \mathrm{aA}$ & $26,0 \mathrm{aA}$ & $16,0 \mathrm{aB}$ \\
\hline Nabo forrageiro & 1,0 & 1,0 & $2,0 \mathrm{aA}$ & $1,2 \mathrm{aB}$ & $6,0 \mathrm{aA}$ & $6,5 \mathrm{aA}$ & $16,0 \mathrm{cA}$ & $14,0 \mathrm{aA}$ \\
\hline Aveia & 1,0 & 1,0 & $2,0 \mathrm{aA}$ & $1,2 \mathrm{aB}$ & $6,0 \mathrm{aA}$ & $6,5 \mathrm{aA}$ & $12,0 \mathrm{~dB}$ & $16,0 \mathrm{aA}$ \\
\hline Feijão & 1,0 & 1,0 & $2,0 \mathrm{aA}$ & $1,0 \mathrm{aB}$ & $6,0 \mathrm{aA}$ & $6,0 \mathrm{aA}$ & $13,5 \mathrm{dA}$ & $16,0 \mathrm{aA}$ \\
\hline Trigo & 1,0 & 1,0 & $2,0 \mathrm{aA}$ & $1,0 \mathrm{aB}$ & $6,0 \mathrm{aA}$ & $6,0 \mathrm{aA}$ & $18,0 \mathrm{cA}$ & $16,0 \mathrm{aA}$ \\
\hline Fcalc & \multicolumn{2}{|c|}{-} & \multicolumn{2}{|c|}{1,03} & \multicolumn{2}{|c|}{1,96} & \multicolumn{2}{|c|}{15,12} \\
\hline $\mathrm{CV}(\%)$ & \multicolumn{2}{|c|}{ - } & \multicolumn{2}{|c|}{19,19} & \multicolumn{2}{|c|}{12,85} & \multicolumn{2}{|c|}{11,17} \\
\hline
\end{tabular}

Médias seguidas da mesma letra minúscula na coluna e maiúscula na linha não diferem entre si segundo o teste de Scott-Knott à $5 \%$ de probabilidade.

Para a avaliação feita aos 28 DAE, verificouse que os tratamentos com palha de nabo forrageiro, aveia, feijão e trigo reduziram o desenvolvimento de corda de viola se comparado à testemunha sem palha e a palha de girassol. A redução do número de folhas é um fato importante, uma vez que plantas daninhas em estádios de desenvolvimento menos avançados são mais suscetíveis ao controle químico.

Os dados de massa seca das plantas de corda de viola estão expostos na Tabela 3. De maneira geral, não foram observadas diferenças significativas para esta variável para os diferentes tipos de irrigação utilizados, exceto para a palhada aveia, na qual foi observada menor massa seca das plantas de corda de viola quando a irrigação foi feita por capilaridade. A menor massa seca deve-se ao menor número de plantas de corda de viola neste tratamento (Tabela 1). TREZZI et al. (2006) estudando o efeito de palhadas sobre o desenvolvimento de E. heterophylla, verificaram que não houve efeito da palhada sobre a 
massa seca desta espécie e concluíram que o número de folhas de leiteiro é um indicador mais adequado para se avaliar os efeitos negativos dos resíduos de sorgo e milho do que a massa seca das plantas.

Na tabela 4 estão apresentados os resultados para número de plantas de leiteiro nas avaliações realizadas aos 7, 14, 21 e 28 DAE.

$\mathrm{Na}$ primeira avaliação (7 $\mathrm{DAE}$ ) não foi observada diferença significativa entre as palhadas testadas. Nas demais avaliações verificou-se que quando a irrigação foi por capilaridade, as palhadas de nabo forrageiro e aveia proporcionaram redução significativa no número de plantas de leiteiro, se comparado as demais palhadas testadas. TREZZI et al. (2006) estudando palha de aveia na supressão de $E$. heterophylla verificaram menor velocidade de emergência desta planta daninha, no entanto, não obtiveram redução no número de plântulas emergidas.

SPIASSI et al. (2011) estudando o efeito de diferentes palhadas sobre o desenvolvimento inicial da cultura do milho, notaram que quando esta cultura foi semeada em área com aveia e nabo forrageiro o

Tabela 3 - Massa seca das plantas de corda de viola (Ipomoea triloba) aos 28 dias após a emergência em solos com diferentes coberturas vegetais. Campo Mourão, 2014.

Table 3 - Dry mass of morning glory (Ipomoea triloba) at 28 days after emergence in soils with different vegetation cover. Campo Mourão, 2014.

\begin{tabular}{ccc}
\hline & \multicolumn{3}{c}{ Massa Seca $(\mathrm{g})$} \\
\cline { 2 - 4 } Palhada & \multicolumn{3}{c}{ Corda de viola } \\
\cline { 2 - 4 } & Superficial & Sub-superfcial \\
\cline { 2 - 4 } Sem palha & $5,67 \mathrm{aA}$ & $4,66 \mathrm{aA}$ \\
Girassol & $6,92 \mathrm{aA}$ & $4,75 \mathrm{aA}$ \\
Nabo forrageiro & $6,03 \mathrm{aA}$ & $5,20 \mathrm{aA}$ \\
Aveia & $5,25 \mathrm{aA}$ & $2,59 \mathrm{aB}$ \\
Feijão & $5,71 \mathrm{aA}$ & $5,13 \mathrm{aA}$ \\
Trigo & $5,36 \mathrm{aA}$ & $4,95 \mathrm{aA}$ \\
\hline Fcalc & \multicolumn{3}{|}{} \\
CV(\%) & \multicolumn{3}{c}{0,54} & \\
\hline
\end{tabular}

Médias seguidas da mesma letra minúscula na coluna e maiúscula na linha não diferem entre si segundo o teste de Scott-Knott à 5\% de probabilidade.

Tabela 4 - Número de plantas de leiteiro (Euphorbia heterophylla) após a emergência em solos com diferentes coberturas vegetais. Campo Mourão, 2014.

Table 4 - Number of poinsettia plants (Euphorbia heterophylla) after emergence in soils with different vegetation cover. Campo Mourão, 2014.

\begin{tabular}{|c|c|c|c|c|c|c|c|c|}
\hline \multirow{3}{*}{ Palhada } & \multicolumn{8}{|c|}{ Número de plantas de leiteiro } \\
\hline & \multicolumn{2}{|c|}{$7 \mathrm{DAE}$} & \multicolumn{2}{|c|}{$14 \mathrm{DAE}$} & \multicolumn{2}{|c|}{$21 \mathrm{DAE}$} & \multicolumn{2}{|c|}{$28 \mathrm{DAE}$} \\
\hline & Sup. & Sub. & Sup. & Sub. & Sup. & Sub. & Sup. & Sub. \\
\hline Sem palha & $12,2 \mathrm{aA}$ & $14,5 \mathrm{aA}$ & $12,5 \mathrm{aA}$ & $14,5 \mathrm{aA}$ & $12,5 \mathrm{aA}$ & $12,7 \mathrm{bA}$ & $12,5 \mathrm{aA}$ & $15,0 \mathrm{aA}$ \\
\hline Girassol & $14,7 \mathrm{aA}$ & $10,5 \mathrm{aB}$ & $14,7 \mathrm{aA}$ & $14,2 \mathrm{aA}$ & $14,7 \mathrm{aA}$ & $15,5 \mathrm{aA}$ & $16,0 \mathrm{aA}$ & $14,7 \mathrm{aA}$ \\
\hline Nabo forrageiro & $14,5 \mathrm{aA}$ & $9,7 \mathrm{aB}$ & $14,5 \mathrm{aA}$ & $10,7 \mathrm{bB}$ & $14,5 \mathrm{aA}$ & $12,5 \mathrm{bA}$ & $14,5 \mathrm{aA}$ & $10,7 \mathrm{bA}$ \\
\hline Aveia & $13,0 \mathrm{aA}$ & $10,2 \mathrm{aA}$ & $13,0 \mathrm{aA}$ & $10,7 \mathrm{bA}$ & $11,7 \mathrm{aA}$ & $10,0 \mathrm{bA}$ & $13,0 \mathrm{aA}$ & $10,2 \mathrm{bA}$ \\
\hline Feijão & $12,2 \mathrm{aA}$ & $13,2 \mathrm{aA}$ & $12,2 \mathrm{aA}$ & $14,0 \mathrm{aA}$ & $12,7 \mathrm{aA}$ & $14,0 \mathrm{aA}$ & $12,2 \mathrm{aA}$ & $13,5 \mathrm{aA}$ \\
\hline Trigo & $11,2 \mathrm{aA}$ & $12,5 \mathrm{aA}$ & $11,7 \mathrm{aB}$ & $16,0 \mathrm{aA}$ & $11,7 \mathrm{aB}$ & $16,0 \mathrm{aA}$ & $12,2 \mathrm{aA}$ & $16,0 \mathrm{aA}$ \\
\hline Fcalc & \multicolumn{2}{|c|}{2,48} & \multicolumn{2}{|c|}{3,09} & \multicolumn{2}{|c|}{1,62} & \multicolumn{2}{|c|}{2,55} \\
\hline $\mathrm{CV}(\%)$ & \multicolumn{2}{|c|}{22,23} & \multicolumn{2}{|c|}{18,03} & \multicolumn{2}{|c|}{19,18} & \multicolumn{2}{|c|}{19,86} \\
\hline
\end{tabular}

Médias seguidas da mesma letra minúscula na coluna e maiúscula na linha não diferem entre si segundo o teste de ScottKnott à 5\% de probabilidade. 
seu desenvolvimento inicial foi afetado, havendo menor índice de velocidade de emergência (IVE), comprimento e massa seca da parte aérea e raiz.

Quando a irrigação foi superficial não foram observadas diferenças entre as palhas testadas.

O número de folhas das plantas de leiteiro está exposto na Tabela 5. Para esta variável não foram observadas diferenças marcantes entre as palhadas utilizadas. Na avaliação aos $28 \mathrm{DAE}$, verificou-se que as plantas de leiteiro encontravam-se em estádio de desenvolvimento mais avançado quando a irrigação foi feita por capilaridade, isso para todas as palhadas testadas, inclusive para o tratamento sem palha.

Quanto à massa seca das plantas de leiteiro, para a irrigação subsuperficial, não foram observadas diferenças significativas entre as diferentes palhadas estudadas (Tabela 6).

$\mathrm{Na}$ irrigação superficial as palhadas de nabo forrageiro, aveia, feijão e trigo proporcionaram redução significativa no acúmulo de massa seca das plantas de leiteiro, se comparadas à testemunha sem palha e a palha do girassol (Tabela 6).

Tabela 5 - Número de folhas das plantas de leiteiro (Euphorbia heterophylla) após a emergência em solos com diferentes coberturas vegetais. Campo Mourão, 2014.

Table 5 - Number of poinsettia leaves (Euphorbia heterophylla) after emergence in soils with different vegetation cover. Campo Mourão, 2014.

\begin{tabular}{|c|c|c|c|c|c|c|c|c|}
\hline \multirow{3}{*}{ Palhada } & \multicolumn{8}{|c|}{ Número de folhas de plantas de leiteiro } \\
\hline & \multicolumn{2}{|c|}{$7 \mathrm{DAE}$} & \multicolumn{2}{|c|}{$14 \mathrm{DAE}$} & \multicolumn{2}{|c|}{$21 \mathrm{DAE}$} & \multicolumn{2}{|c|}{$28 \mathrm{DAE}$} \\
\hline & Sup. & Sub. & Sup. & Sub. & Sup. & Sub. & Sup. & Sub. \\
\hline Sem palha & $1,0 \mathrm{bA}$ & $0,5 \mathrm{bB}$ & 2,0 & 2,0 & $6,0 \mathrm{aA}$ & $6,0 \mathrm{bA}$ & $10,0 \mathrm{aB}$ & $17,0 \mathrm{aA}$ \\
\hline Girassol & $2,0 \mathrm{aA}$ & $1,0 \mathrm{aB}$ & 2,0 & 2,0 & $6,0 \mathrm{aA}$ & $6,0 \mathrm{bA}$ & $10,0 \mathrm{aB}$ & $17,5 \mathrm{aA}$ \\
\hline Nabo forrageiro & $2,0 \mathrm{aA}$ & $1,0 \mathrm{aB}$ & 2,0 & 2,0 & $6,0 \mathrm{aA}$ & $6,0 \mathrm{bA}$ & $10,0 \mathrm{aB}$ & $18,0 \mathrm{aA}$ \\
\hline Aveia & $2,0 \mathrm{aA}$ & $1,0 \mathrm{aB}$ & 2,0 & 2,0 & $6,0 \mathrm{aA}$ & $5,5 \mathrm{cB}$ & $10,0 \mathrm{aB}$ & $16,5 \mathrm{aA}$ \\
\hline Feijão & $2,0 \mathrm{aA}$ & $1,0 \mathrm{aB}$ & 2,0 & 2,0 & $6,0 \mathrm{aA}$ & $6,0 \mathrm{bA}$ & $10,0 \mathrm{aB}$ & $16,0 \mathrm{aA}$ \\
\hline Trigo & $2,0 \mathrm{aA}$ & $1,0 \mathrm{aB}$ & 2,0 & 2,0 & $6,0 \mathrm{aB}$ & $8,0 \mathrm{aA}$ & $10,0 \mathrm{aB}$ & $17,5 \mathrm{aA}$ \\
\hline Fcalc & \multicolumn{2}{|c|}{3,0} & \multicolumn{2}{|c|}{ - } & \multicolumn{2}{|c|}{18,6} & \multicolumn{2}{|c|}{1,05} \\
\hline $\mathrm{CV}(\%)$ & \multicolumn{2}{|c|}{12,12} & \multicolumn{2}{|c|}{ - } & \multicolumn{2}{|c|}{4,71} & \multicolumn{2}{|c|}{7,49} \\
\hline
\end{tabular}

Médias seguidas da mesma letra minúscula na coluna e maiúscula na linha não diferem entre si segundo o teste de Scott-Knott à 5\% de probabilidade.

Tabela 6 - Massa seca das plantas de leiteiro (Euphorbia heterophylla) aos 28 dias após a emergência em solos com diferentes coberturas vegetais. Campo Mourão, 2014.

Table 6 - Dry mass of poinsettia plants (Euphorbia heterophylla) at 28 days after emergence in soils with different vegetation cover. Campo Mourão, 2014.

\begin{tabular}{ccc}
\hline Palhada & \multicolumn{3}{c}{ Massa Seca $(\mathrm{g})$} \\
\cline { 2 - 4 } & \multicolumn{3}{c}{ Leiteiro } \\
\cline { 2 - 4 } & Superficial & Sub-superfcial \\
\hline Sem palha & $11,60 \mathrm{aA}$ & $4,98 \mathrm{aB}$ \\
Girassol & $13,52 \mathrm{aA}$ & $7,67 \mathrm{aB}$ \\
Nabo forrageiro & $6,85 \mathrm{bA}$ & $6,05 \mathrm{aA}$ \\
Aveia & $4,87 \mathrm{bA}$ & $5,52 \mathrm{aA}$ \\
Feijão & $5,21 \mathrm{bA}$ & $4,68 \mathrm{aA}$ \\
Trigo & $5,56 \mathrm{bA}$ & $6,47 \mathrm{aA}$ \\
\hline Fcalc & \multicolumn{3}{c}{} \\
CV(\%) & 7,91 & \\
\hline
\end{tabular}

Médias seguidas da mesma letra minúscula na coluna e maiúscula na linha não diferem entre si segundo o teste de Scott-Knott à $5 \%$ de probabilidade. 
Esses resultados confirmam os obtidos para a variável número de plantas por vaso, pois estas palhadas proporcionaram menor infestação de plantas de leiteiro por vaso (Tabela 4).

Esses resultados corroboram com trabalhos desenvolvidos por RIZZARDI et al. (2006), que verificaram que a presença de palha de nabo forrageiro é um importante fator de controle de plantas daninhas. Com $6 \mathrm{t} \mathrm{ha}^{-1}$ de palha desta cultura, foram verificados níveis de controle de até $61 \%$ para papuã (Urochloa plantaginea) e $59 \%$ para picão-preto (Bidens pilosa e B. subalternans).

Outro estudo realizado por ALMEIDA (1991) confirmou o efeito alelopático das palhadas de trigo e aveia sobre o desenvolvimento radicular de plantas de E. heterophylla, através de estudos com extrato aquoso destas coberturas mortas. Porém, este efeito alelopático é muito específico tanto em relação às plantas de onde provém o aleloquímico, quanto às espécies sobre quais atuam, por isso, normalmente nestes tipos de trabalhos existem grande variabilidade entre os fatores estudados.

Em suma, verificou-se que palhada das culturas auxiliam no controle de plantas daninhas. Com o seu uso não será dispensado o controle químico, no entanto, poderá auxiliar para reduzir a infestação e retardar o desenvolvimento de algumas espécies o que facilita o controle com herbicidas, contribuindo para o manejo integrado de plantas daninhas.

\section{CONCLUSÃO}

As palhadas de nabo forrageiro, aveia, feijão e trigo, quando recebem irrigação superficial, promovem menor desenvolvimento das plantas de corda de viola e menor acúmulo de massa seca para as plantas de leiteiro.

\section{REFERÊNCIAS}

ALMEIDA FS. 1991. Efeitos alelopáticos de resíduos vegetais. Pesq. Agropec. Bras. 26: 221-236.

CARVALHO SIC. 1993. Caracterização dos efeitos alelopáticos de Brachiaria brizantha cv. Marandu no estabelecimento das plantas de Stylosanthes guianensis var. vulgaris cv. Bandeirante. Dissertação (Mestrado em Zootecnia). Viçosa: UFV. 72p.

CORREIA N et al. 2006. Influencia do tipo e da quantidade de resíduos vegetais na emergência de plantas daninhas. Planta Daninha 24: 245-253.

EMBRAPA - EMPRESA BRASILEIRA DE PESQUISA
AGROPECUÁRIA. 2013. Centro Nacional de Pesquisas de Solos. Sistema Brasileiro de Classificação de Solos. 3. ed., Rio de Janeiro: Embrapa Solos. 353 p.

FERREIRA DF. 2011. Sisvar: a computer statistical analysis system. Ci. Agrotec. 35: 1039-1042.

GABRIEL FILHO A et al. 2003. Profundidade e espaçamento da mandioca no plantio direto na palha. $\mathrm{Ci}$. Rural 33: 461-467.

HARAMOTO ER \& GALLANDT ER. 2004. Brassica cover cropping for weed management: A review. Renew. Agric. Food Syst. 19: 187-198.

MELO AV et al. 2007. Dinâmica populacional de plantas daninhas em cultivo de milho-verde nos sistemas orgânico e tradicional. Planta Daninha 25: 521-527.

MIRÓ CP et al. 1998. Alelopatia de frutos de erva-mate (Ilex paraguariensis) no desenvolvimento do milho. Pesq. Agropec. Bras. 33: 1261-1270.

MORAES PVD et al. 2011. Alelopatia de plantas de cobertura na superfície ou incorporadas ao solo no controle de Digitaria spp. Planta Daninha 29: 963-973.

NOCE MA et al. 2008. Influência da palhada de gramíneas forrageiras sobre o desenvolvimento da planta de milho e das plantas daninhas. Rev. Bras. Milho Sorgo 7: 265-278.

NORWORTHY JK. 2003. Allelopathic potencial of wild radish (Raphanus raphanistrum). Weed Technol. 17: 307313.

OLIVEIRA JUNIOR RS et al. 2014. Grass straw mulching to suppress emergence and early growth of weeds. Planta Daninha 32: 11-17.

PIRES FR et al. 2008. Manejo de plantas e cobertura antecessoras à cultura da soja em plantio direto. Ceres 55 : 94-101.

PITELLI R \& DURIGAN JC. 2001. Ecologia das plantas daninhas no sistema de plantio direto. In: ROSSELLO RD. Siembra directa en el Cono Sur. Montevideo: PROCISUR. p.203-210.

RICE EL. 1984. Allelopathy. 2.ed.,New York: Academic Press.

RIZZARDI MA et al. 2006. Controle de plantas daninhas em milho em função de quantidades de palha de nabo forrageiro. Planta Daninha 24: 263-270.

SPIASSI A et al. 2011. Alelopatia de palhadas de coberturas de inverno sobre o crescimento inicial de milho. Semina. Ci. Agrar. 32: 577-582.

TREZZI MM et al. 2006. Efeitos de resíduos da parte aérea de sorgo, milho e aveia na emergência e no desenvolvimento de plântulas de leiteiro (Euphorbia heterophylla) resistentes a inibidores de ALS. Planta Daninha 24: 443-450.

TREZZI MM \& VIDAL RA. 2004. Potencial de utilização de cobertura vegetal de sorgo e milheto na supressão de plantas daninhas em condição de campo: II - Efeito da cobertura morta. Planta Daninha 22: 1-10. 